https://doi.org/10.36396/MS.2019.15.4.002

\title{
Что мы знаем сегодня об отечественном тромболитическом препарате рекомбинантная проурокиназа (пуролаза)
}

\author{
С.Г. МИАЕНЬКИНА, Е.П. АЕАЬВЕР, А.А. БЕАОГУРОВ, Р.Ш. БИБИААШВИАИ, Е.В. АРЗАМАСЦЕВ, \\ И.И. СТАРОВЕРОВ
}

НМИЦ кардиологии Минздрава России, Москва

\begin{abstract}
Резюме
В обзоре представлены основные Аанные о создании отечественного тромболитического препарата III поколения рекомбинантной проурокиназы и применении ее у пациентов с острым инфарктом миокарда с подьемом сегмента ST (ИМпST). Современные рекоменАации отАают предпочтение первичному чрескожному коронарному вмешательству (ЧКВ). ОАнако ряд ^огистических и технических особенностей нередко делает проведение ЧКВ в рекомендованные сроки невозможным и медикаментозная реперфузия остается методом выбора. Своевременная тромболитическая терапия (ТАТ) позволяет уменьшить время Ао начала реперфузии и улучшить прогноз больного. Накоплен значительный опыт Аогоспитального и госпитального применения рекомбинантной проурокиназы. В статье рассмотрены результаты основных исследований эффективности и безопасности, а также особенностей применения рекомбинантной проурокиназы, в том числе при использовании фармакоинвазивного подхода к лечению ИМпST.

КАючевые слова: острый инфаркт миокарда с подьемом сегмента ST, тромболитическая терапия, пуролаза, рекомбинантная проуроки наза, фармакоинвазивный похход.
\end{abstract}

\section{What we know today about thrombolytic drug recombinant prourokinase(purolase) produced in Russia}

\author{
S.G. MILENKINA, E.P. DELVER, A.A. BELOGUROV, R.SH. BIBILASHVILLI, E.V. ARZAMASTSEV, I.I. STAROVEROV
}

National Medical Research Center of Cardiology. 15a, 3rd Cherepkovskaya str., Moscow, 121552, Russian Federation.

\begin{abstract}
Summary
The review presents the main data on the development of thrombolytic drug of the III generation of recombinant prourokinase produced in Russia and its administration in patients with acute myocardial infarction with ST segment elevation (STEMI). Current guidelines prefer primary percutaneous coronary intervention (PCI). However, a number of logistical and technical aspects often make it impossible to carry out $\mathrm{PCl}$ within the recommended time, and drug reperfusion remains the method of choice. Well-timed thrombolytic therapy (TLT) can reduce the time before reperfusion and improve the patient's prognosis. Significant experience in pre-hospital and hospital is adepted at use of recombinant prourokinase. The article considers the results of the main studies of the effectiveness and safety, as well as the aspects of the use of recombinant prourokinase, including the use of pharmacoinvasive approach to the treatment of STEMI.
\end{abstract}

Key word: sacute myocardial infarction with ST-segment elevation, thrombolytic therapy, Purolase, pharmacoinvasive approach.

\footnotetext{
Сведения об авторах:

Миленькина Софья Григорьевна - аспирант отьела неотложной кардиологии ФГБУ «НМИЦ кардиологии» Минздрава России. Е-таі:: baranova.sg@gmail.com.

Аельвер Евгений Петрович - к. б. н.; старший научный сотрудник, ФГБУ «НМИШ кардиологии» Минздрава России.

Белогуров Анатолий Алексанцрович - к. б. н.; ведуший научный сотрудник ФГБУ «НМИЦ кардиологии» Минздрава России.

Бибилашвияи Роберт Шалвович — к. ф-м. н.; ведуший научный сотрудник,

руководитель ^аборатории генной инженерии ФГБУ «НМИЦ кардиологии» Минздрава России. SPIN-код 2700-8672.

Арзамасцев Евгений Вениаминович - А. М. н., профессор, главный научный сотрудник, руководитель лаборатории лекарственной токсикологии ФГБУ «НМИШ кардиологии» Минздрава России. SPIN-код 1840-6571.

Староверов Игорь Иванович - А. М. н., главный научный сотрудник отьела неотложной кардиологии ФГБУ «НМИШ карАиологии» МинзАрава России.
}

(C) Коммектив авторов 


\section{Введение}

Инфаркт миокарда - заболевание, являющееся одной из ведущих причин смертности и инвалидизации в развитых странах. В основе патогенеза ишемического некроза миокарда лежит нарушение кровотока в инфаркт-связанной коронарной артерии. Максимально быстрое восстановление кровотока во многом определяет исход заболевания (размер зоны некроза, степень нарушения сократительной функции миокарда, а также частоту летальных исходов).

Сегодня в рекомендациях по лечению больных с острым инфарктом миокарда с подъемом сегмента ST (ИМпST) отдается предпочтение двум основным реперфузионным стратегиям: тромболитической терапии (ТЛТ) с последующим эндоваскулярным вмешательством и чрескожному коронарному вмешательству (ЧКВ) [1, 2]. Успешно проведенная ТЛТ приводит к восстановлению проходимости сосуда, однако в большинстве случаев в сосуде остается резидуальный стеноз, создающий основу для развития повторных коронарных событий. Преимущество ЧКВ над ТЛТ очевидно в связи с возможностью проведения ангиопластики коронарной артерии при условии соблюдения определенных временных и организационных требований.

Возможность доставки больного с ИМпST в специализированный стационар, оснащенный лабораторией ангиографии, решена не во всех регионах РФ. Именно поэтому в рекомендациях национальных и мировых экспертов ТЛТ остается актуальным методом реперфузионной терапии.

В последние годы в рекомендациях появилась информация о возможности использования фармакоинвазивного подхода, то есть проведения ЧКВ через 3-24 часа после успешной ТЛТ или в более ранние сроки при отсутствии восстановления коронарного кровотока.

\section{История создания препарата}

История создания тромболитического препарата третьего поколения пуролаза (рекомбинантная проурокиназа) началась в 1984 году, когда по инициативе академика Е.И. Чазова в лаборатории генной инженерии Института экспериментальной кардиологии (ИЭК) (руководитель - Р.Ш. Бибилашвили) и отделе неотложной кардиологии Института клинической кардиологии (М.Я. Руда, И.И. Староверов) в Российском кардиологическом научно-производственным комплексе МЗ РФ (сегодня - НМИЦ кардиологии МЗ РФ) в качестве прототипа действующего начала препарата была выбрана специфическая протеаза человека - активатор плазминогена урокиназного типа, или проурокиназа.

В лаборатории генной инженерии Института экспериментальной кардиологии с помощью скрининга библиотек кДНК, полученных на основе мРНК-клеток человека, были созданы прототипы плазмид, содержащих ген модифицированной проурокиназы человека, способных в клетках E. coli синтезировать под контролем бактериальных промоторов активный белок. В связи с практической направленностью проекта создания препарата рекомбинантная проуроки- наза в лаборатории генной инженерии ИЭК совместно с ЭПМБП РКНПК МЗ РФ была создана технология производства готовой лекарственной формы препарата и налажено производство тромболитического препарата рекомбинантной проурокиназы для проведения его лабораторных, доклинических и клинических исследований.

Исследования энзимологических и фармакокинетических свойств препарата рекомбинантной проурокиназы были проведены в лаборатории генной инженерии Института экспериментальной кардиологии (ИЭК). Доклинические исследования препарата были проведены в лаборатории лекарственной токсикологии ИЭК (руководитель - Е.В. Арзамасцев, РКНПК МЗ РФ). Клинические исследования препарата для лечения инфаркта миокарда, которыми руководили М.Я. Руда и И.И. Староверов Института клинической кардиологии (ИКК), были выполнены в ряде кардиологических клиник России.

\section{Свойства действующего вещества}

Препарат отечественного производства рекомбинантная проурокиназа представляет собой полученный генно-инженерным путем продукт экспрессии гена модифицированной проурокиназы человека в бактериях E. coli - одноцепочную проурокиназу. Как и все тромболитические препараты 2-го и 3-го поколения, рекомбинантная проурокиназа вызывает значительно менее выраженный системный фибринолиз, в отличие от препаратов 1-го поколения (стрептокиназы и мочевой урокиназы). Изменение аминокислотной последовательности ее $\mathrm{N}$-концевого рецептор-связывающего домена привело к невозможности связывания препарата со специфическими рецепторами на поверхности клеток и, таким об-

\section{Рисунок 1. Проурокиназа имеет моцульную структуру} и состоит из трех доменов: рецептор-связываюшего домена, крингель-цомена и каталитического домена, характерного ц^я сериновых протеаз. Рекомбинантная проурокиназа является модифицированной проурокиназой человека и отличается от природного фермента модификашией $\mathrm{N}$ - концевого рецептор-связываюшего хомена, осушествленной при помоши замены его первых 24 аминокислотных остатков (показано зеленым цветом) [3].

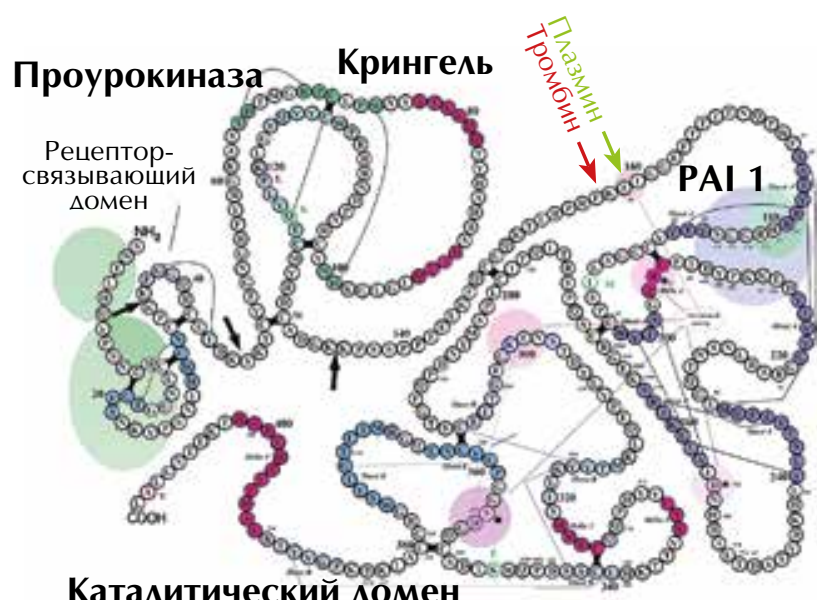

Каталитический хомен 
разом, исключило активизацию регуляторных процессов, контролирующих миграции клеток и ремоделирование тканей, но никак не повлияло на вторичную структуру «протеазной части» молекулы и, соответственно, на ферментативные и фибринолитические свойства препарата.

Рекомбинантная проурокиназа преимущественно активирует фибрин-связанный плазминоген, имеющий иную конформацию по сравнению с циркулирующим в кровотоке плазминогеном, в плазмин. Кроме того, показано, что в области тромба проурокиназа не ингибируется специфическими ингибиторами, присутствующими в плазме крови. Сама одноцепочечная молекула проурокиназы под воздействием плазмина превращается в двухцепочечную молекулу, которая, в отличие от одноцепочной проформы, значительно более активна в отношении фибрин-связанного плазминогена. Образуется «цепная реакция» взаимодействия препарата с плазминогеном тромба, в результате которой тромб разрушается.

Непосредственный аналог рекомбинантной проурокиназы на сегодняшний день отсутствует. Наиболее близким его аналогом являются препараты актилизе (альтеплаза) и метализе (тенектеплаза), основанные на использовании другого белка человека - активатора плазминогена тканевого типа.

Кроме того, рекомбинантная проурокиназа, в отличие от препаратов, основанных на активаторе плазминогена тканевого типа, основана на действии другого человеческого белка - проурокиназа, который был модифицирован для терапевтических целей и, как показал клинический опыт успешного использования в кардиологии, офтальмологии и нейрохирургии, обладает не только эффективностью, но и высокой безопасностью.

Эти уникальные свойства рекомбинантной проурокиназы, по-видимому, связаны с тем, что препарат, в отличие от препаратов альтеплаза и тенектеплаза, является производным проурокиназы и не обладает нейротоксическими свойствами, характерными для препаратов, основанных на тканевом активаторе плазминогена. В некоторых современных исследованиях показано, что действующее начало препаратов альтеплаза и тенектеплаза - тканевой активатор плазминогена - обладает способностью к нарушению гематоэнцефалического барьера

Таблица 1. Сравнительная характеристика тромболитических препаратов.

\begin{tabular}{|c|c|c|c|c|c|}
\hline Характеристика & $\begin{array}{c}\text { Пуролаза (проурокиназа } \\
\text { рекомбинантная) }\end{array}$ & Актилизе (альтепмаза) & $\begin{array}{c}\text { Метализе } \\
\text { (тенектеплаза) }\end{array}$ & Стрептокиназа & \\
\hline $\begin{array}{l}\text { Прироха } \\
\text { препарата }\end{array}$ & $\begin{array}{c}\text { Белок человека, полученный } \\
\text { биотехнологическим путем }\end{array}$ & $\begin{array}{c}\text { Белок человека, } \\
\text { полученный } \\
\text { биотехнологическим } \\
\text { путем }\end{array}$ & $\begin{array}{c}\text { Белок человека, } \\
\text { полученный } \\
\text { биотехнологическим } \\
\text { путем }\end{array}$ & $\begin{array}{c}\text { Бактериальный } \\
\text { белок }\end{array}$ & \\
\hline Тромболитик & 3-го поколения & 2-го поколения & 3-го поколения & 1-го поколения & \\
\hline $\begin{array}{l}\text { Механизм } \\
\text { действия } \\
\text { (активация } \\
\text { пмазминогена) }\end{array}$ & $\begin{array}{c}\text { Модифицированный } \\
\text { фибринспецифичный } \\
\text { активатор } \\
\text { плазминогенаурокиназного } \\
\text { типа (протеазная конверсия } \\
\text { фибринсвязанного } \\
\text { плазминогена в плазмин) }\end{array}$ & $\begin{array}{c}\text { Фибринспецифичный } \\
\text { активатор плазминогена } \\
\text { тканевого типа } \\
\text { (протеазная конверсия } \\
\text { плазминогена в плазмин в } \\
\text { области тромба) }\end{array}$ & $\begin{array}{c}\text { Модифичированный } \\
\text { фибринспецифичный } \\
\text { активатор } \\
\text { плазминогена } \\
\text { тканевого типа } \\
\text { (протеазная конверсия } \\
\text { плазминогена в } \\
\text { плазмин в области } \\
\text { тромба) }\end{array}$ & $\begin{array}{c}\text { Фибрин- } \\
\text { неспецифичный } \\
\text { активатор } \\
\text { плазминогена } \\
\text { (активация } \\
\text { тотального } \\
\text { плазминогена } \\
\text { путем } \\
\text { образования } \\
\text { комплекса } \\
\text { стрептокиназа- } \\
\text { плазминоген) }\end{array}$ & \\
\hline $\begin{array}{l}\text { Время } \\
\text { полувыведения }\end{array}$ & 30-42 минуты & 4-8 минут & & 20-24 минуты & $\begin{array}{l}15-20 \\
\text { минут }\end{array}$ \\
\hline $\begin{array}{l}\text { Системный } \\
\text { фибринолиз }\end{array}$ & Не вызывает & Не вызывает & Не вызывает & Вызывает & \\
\hline $\begin{array}{l}\text { Частота } \\
\text { тромботических } \\
\text { реоккАюзий }\end{array}$ & $4-5 \%$ & $10-15 \%$ & $10-15 \%$ & $10 \%$ & \\
\hline $\begin{array}{l}\text { Иммунные } \\
\text { реакшии }\end{array}$ & $\begin{array}{c}\text { Не вызывает иммунных } \\
\text { реакций }\end{array}$ & $\begin{array}{c}\text { Не вызывает иммунных } \\
\text { реакций }\end{array}$ & $\begin{array}{c}\text { Не вызывает } \\
\text { иммунных реакций }\end{array}$ & $\begin{array}{c}\text { Сильный } \\
\text { иммуноген }\end{array}$ & \\
\hline $\begin{array}{l}\text { Вирусная } \\
\text { контаминашия }\end{array}$ & Исключена & Исключена & Исключена & Исключена & \\
\hline $\begin{array}{l}\text { Способ в/в } \\
\text { введения }\end{array}$ & Болюс & $\begin{array}{c}\text { Схема «Болюс + инфузия» } \\
\text { возможна }\end{array}$ & Болюс + инфузия & Болюс & Инфузия \\
\hline $\begin{array}{l}\text { Возможность } \\
\text { применения на } \\
\text { догоспитальном } \\
\text { этапе. Оценка } \\
\text { сложности } \\
\text { процедуры } \\
\text { введения }\end{array}$ & $\begin{array}{c}\text { Возможно. Оптимальная } \\
\text { схема введения }\end{array}$ & $\begin{array}{c}\text { Возможно. Сложная } \\
\text { прочедура, вк^ючаюшая в } \\
\text { себя использование } \Delta в у х \\
\text { инфузионных этапов с } \\
\text { различной кончентрацией } \\
\text { препарата. }\end{array}$ & $\begin{array}{c}\text { Возможно. } \\
\text { Оптимальная схема } \\
\text { введения }\end{array}$ & $\begin{array}{l}\text { Сложно из-за } \\
\text { высокой частоты } \\
\text { геморрагических } \\
\text { осложнений и } \\
\text { Аругих побочных } \\
\text { эффектов. }\end{array}$ & \\
\hline
\end{tabular}


Рисунок 2. Фармакокинетика рекомбинантной

проурокиназы при цозе

6 МАн ME (2 МАн ME болюС + 4 млн МЕ инфузия в течение 60 минут) после окончания болюса и начала инфузии [отчет о клинических исследованиях эффективности и безопасности тромболитического препарата 3-го поколения пуролаза (проурокиназа рекомбинантная).

Генеральный Аиректор ФГУ РКНПК РосмеАтехнологий акацемик Е.И. Чазов. 20/11/2007].
Фармакокинетика пуромазы

Аозы 6 млн МЕ: болюс, 4 млн МЕ 60 мин инфузия. $\mathrm{n}=12$

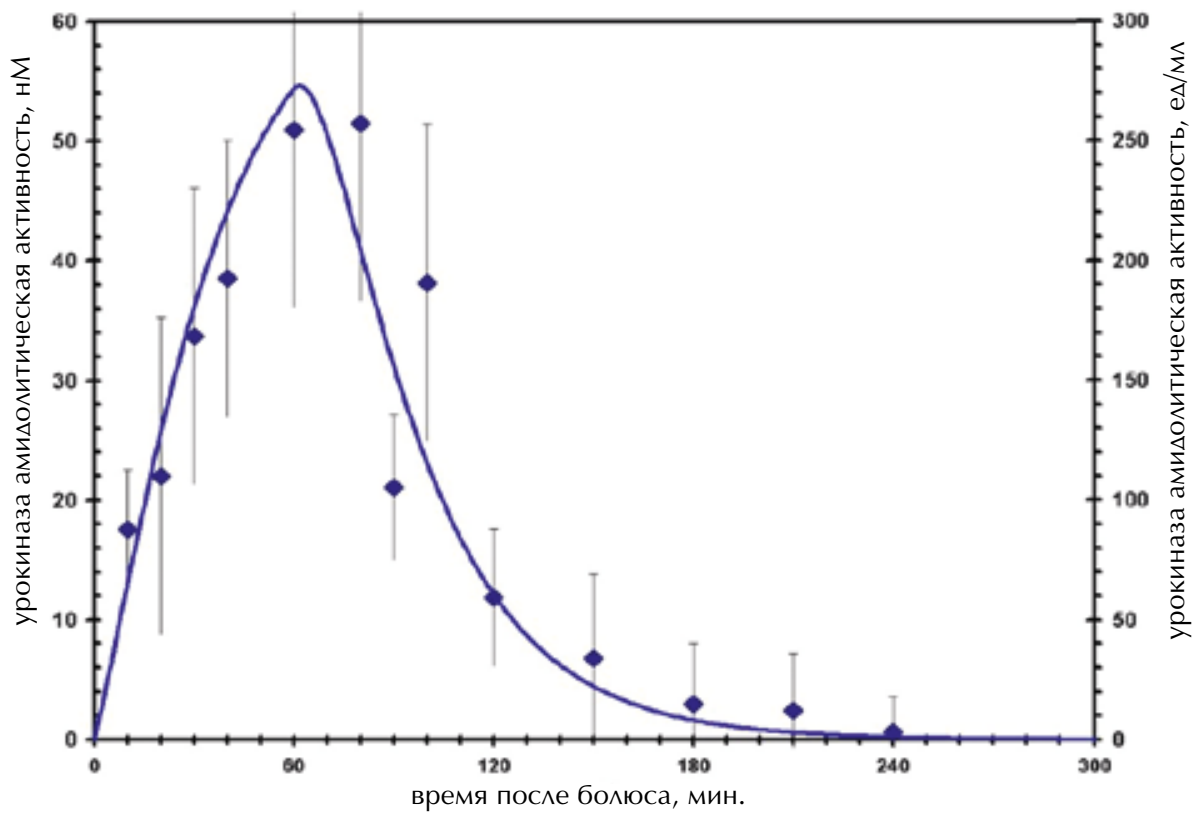

и к последующему специфическому нейротоксическому взаимодействию (специфический протеолиз NMDA peцепторов мозговой ткани) с нервной тканью.

\section{Результаты изучения фармакокинетических} параметров рекомбинантной проурокиназы

Важным результатом модификации структуры рецептор-связывающего домена проурокиназы и ее «высвобождения» из несвязанных с фибринолизисом процессов стало увеличение ее времени жизни в кровотоке. Исследования фармакокинетики рекомбинантной проурокиназы, выполненные на собаках (общепринятая модель для подобного рода исследований), показали, что время полувыведения $\left(\mathrm{T}_{1 / 2}\right)$ препарата составляет $40 \pm 6$ минут, что значительно (примерно в 5 раз) превышает величину этого параметра, характерную для природной проурокиназы (6-9 минут) в аналогичной ситуации. Иодификация активатора плазминогена тканевого типа (тенектеплазы) привела к увеличению времени полувыведения в 5-7 раз (до 20-24 минуты) по сравнению с природным аналогом (альтеплазой) $\left(\mathrm{T}_{1 / 2}=3-5\right.$ минут).

Таблица 2. Фармакокинетические параметры рекомбинантной проурокиназы Аля Аозы 6 ммн ME.

\begin{tabular}{|c|c|c|c|c|c|}
\hline Наименование параметра & $\begin{array}{l}\text { Условное } \\
\text { обозначение }\end{array}$ & Величина & & $\begin{array}{l}\text { Станцартное } \\
\text { отклонение }\end{array}$ & $\begin{array}{c}\text { ЕАиница } \\
\text { измерения }\end{array}$ \\
\hline$\Delta 03 \mathbf{a}$ & & 6000000 & \pm & 60000 & ME \\
\hline Плошахь под кривой & AUC & 21000 & \pm & 3000 & МЕмин./м^ \\
\hline Клиренс абсолютный & $\mathrm{CL}$ & 286 & \pm & 31 & мN/Мин. \\
\hline Константа скорости выведения & k & 0,019 & \pm & 0,004 & 1/мин. \\
\hline Время умержания & MRT & 52 & \pm & 9,2 & мин. \\
\hline Время полувыведения & $\mathrm{T} 1 / 2$ & 36 & \pm & 6,5 & мин. \\
\hline Объем распрехеления & V1 & 14,9 & \pm & 0,8 & китр \\
\hline Максимальная коншентрашия в плазме & Cmax & 273 & \pm & 33 & $\mathrm{ME} / \mathrm{M} \wedge$ \\
\hline $\begin{array}{l}\text { Время достижения наибольшей коншентрации } \\
\text { в плазме }\end{array}$ & $\operatorname{tmax}$ & 66 & \pm & 5,3 & мин. \\
\hline Константа скорости активации & k_a & 0,083 & \pm & 0,017 & 1/мин. \\
\hline Характерное время активашии & MRT_a & 8 & \pm & 2,4 & мин. \\
\hline Время покуактивашии & $\mathrm{t} 1 / 2 \_\mathrm{a}$ & 5,5 & \pm & 0,91 & мин. \\
\hline 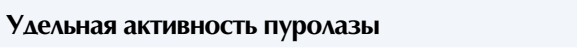 & & 100000 & \pm & 10000 & $\mathrm{ME} / \mathrm{M \Gamma}$ \\
\hline Расчетный объем крови & & 5,5 & \pm & 0,5 & китр \\
\hline Биодоступность в плазме некоррегиров & PB & 25 & \pm & 0,08 & $\%$ \\
\hline
\end{tabular}


С целью более детального изучения фармакокинетических параметров рекомбинантной проурокиназы при лечении ИМ и оптимизации дозы препарата было проведено исследование на 12 пациентах с диагнозом ИМпST различной локализации (10 мужчин, 2 женщины, средний возраст $57 \pm 9$ лет, средний вес $79 \pm 5$ кг). Рекомбинантная проурокиназа вводилась пациентам внутривенно через $2-5(3 \pm 1,3)$ часов после начала приступа в уменьшенной дозе $6000000 \mathrm{ME} \mathrm{(2000} 000 \mathrm{ME} \mathrm{болюс} \mathrm{+} 4000000 \mathrm{ME}$ инфузия в течение 60 минут). Восстановление коронарного кровотока наблюдалось через 30-90 минут от начала введения рекомбинантной проурокиназы у 9 из 2 больных ИМ (75\%). Кривая на рис. 2 показывает усредненные значения активности урокиназы в плазме крови в зависимости от времени сразу после болюса и начала инфузии для рекомбинантной проурокиназы в дозе 6 млн МЕ.

В таблице 2 приведены параметры, используемые для характеристики фармакокинетики препаратов [отчет о клинических исследованиях эффективности и безопасности тромболитического препарата 3-го поколения пуролаза (проурокиназа рекомбинантная). Генеральный директор ФГУ РКНПК Росмедтехнологий академик Е.И. Чазов. 20/11/2007]

Период полувыведения молекулы рекомбинантной проурокиназы в кровотоке человека $\mathrm{T}_{1 / 2}$ составил $36 \pm 6$ мин., что примерно в 4 раза превышает величину данного параметра, характерного для природной формы проурокиназы (6-9 минут).

\section{Результаты доклинических исследований рекомбинантной проурокиназы}

На доклиническом этапе в лаборатории лекарственной токсикологии (руководитель - профессор Е.В. Арзамасцев, РКНПК МЗ РФ) проводились:

- Исследования острой токсичности препарата на СПФ-мышах (specific pathogen free) линии NRMI, белых нелинейных мышах, кроликах и собаках при внутривенном введении. Проурокиназа является малотоксичным веществом в соответствии с принятой классификацией ВО3.

- Исследования субхронической токсичности при внутривенном введении кроликам, собакам. Препарат не оказал влияния на общее состояние, поведение и динамику массы тела; данные общего и биохимического анализов крови оставались в пределах физиологической нормы; при макроскопическом и гистологическом исследованиях общих и местных токсико-аллергических реакций, связанных с действием изучаемого препарата, выявлено не было.

- Изучение мутагенной активности рекомбинантной проурокиназы с проведением следующих исследований: учет генных мутаций на микроорганизмах в тесте Эймса, учет хромосомных аберраций в клетках костного мозга млекопитающих, учет доминантных летальных мутаций в зародышевых клетках мышей, изучение ДНК-повреждающего действия в SOS-хромотесте:

а) в тесте Эймса: результаты исследования показали, что рекомбинантная проурокиназа, в отличие от положи- тельного контроля, не вызывала достоверного числа ревертантов, что свидетельствует об отсутствии мутагенной активности у исследуемого препарата;

б) исследование цитогенетической активности препарата методом учета хромосомных аберраций в клетках костного мозга: в ходе исследования достоверных различий в уровне хромосомных аберраций в клетках костного мозга мышей, подвергшихся воздействию исследуемого препарата, по сравнению с контролем выявлено не было, что свидетельствует об отсутствии мутагенных свойств препарата;

в) изучение влияния препарата на индукцию доминантных летальных мутаций в зародышевых клетках мышей. Результаты исследования показали, что в группе, в которой самцы подвергались воздействию препаратом, постимплантационная смертность не превышала данный показатель в контрольной группе. Ни в один из сроков наблюдения препарат не индуцировал доминантные летальные мутации в зрелых спермиях, поздних сперматидах и ранних сперматидах мышей, что свидетельствует об отсутствии мутагенных свойств у исследуемого препарата;

г) изучение влияния препарата на систему репарации ДНК в SOS-хромотесте. Результаты исследования показали, что рекомбинантная проурокиназа не вызывает активации системы репарации ДНК у E. coli PQ 37, то есть не обладает ДНК-повреждающим действием.

- Эмбриотоксические и тератогенные свойства рекомбинантной проурокиназы изучали на беременных крысах линии Вистар при внутрибрюшинном введении. Результаты исследования показали, что препарат в исследуемых дозах не влиял на динамику массы тела беременных крыс, продолжительность беременности, количество живых эмбрионов, их массу и размер тела, а также на процент пред- и постимплантационной гибели, препарат не обладал эмбриотоксическими и тератогенными свойствами.

- Для изучения аллергизирующих свойств рекомбинантной проурокиназы были проведены исследования его анафилактогенной активности, способности вызывать активную кожную анафилаксию, реакцию гиперчувствительности III типа, реакцию гиперчувствительности замедленного типа, конъюнктивальную реакцию и непрямую реакцию дегрануляции тучных клеток. Результаты исследования показали, что рекомбинантная проурокиназа не обладает аллергизирующими свойствами и не вызывает аллергических реакций немедленного типа.

- Изучение экспериментальной терапии передозировок препарата: введение гордокса (инактиватор калликреина) способствует нормализации параметров свертывания крови на фоне действия проурокиназы в высоких дозах. Результаты доклинических исследований свидетельствуют о низкой токсичности и хорошей переносимости рекомбинантной проурокиназы как при однократном, так и многократном введении животным. У препарата не выявлено мутагенных, эмбриотоксических, тератогенных и аллергизирующих свойств. 


\section{Результаты клинических исследований}

\section{рекомбинантной проурокиназы}

В отделе неотложной кардиологии РКНПК МЗ РФ было проведено клиническое исследование по изучению эффективности и безопасности рекомбинантной проурокиназы в сравнении с препаратом стрептокиназа в комплексной терапии острого инфаркта миокарда. В исследование было включено 237 пациентов с острым инфарктом миокарда продолжительностью не более 6 часов. Препарат рекомбинантной проурокиназы применяли по следующей схеме: $2000000 \mathrm{ME}$ болюс + $6000000 \mathrm{ME}$ инфузия в течение 60 мин. Достижение реперфузии коронарной артерии оценивали по снижению сегмента ST в наиболее информативном отведении ЭКГ более чем на $50 \%$ от исходной элевации через 3 часа от начала ТЛТ. Дополнительно у 21 пациента, получавшего рекомбинантную проурокиназу, и у 30 пациентов, получавших стрептокиназу, проводилась коронарная ангиография (КАГ).

По данным исследований ЭКГ, коронарная реперфузия была достигнута у 176 пациентов (74\%).

По данным коронарографии, к 90-й минуте от начала ТЛТ реперфузия коронарной артерии была достигнута у 29 пациентов, которым вводилась рекомбинантная проурокиназа (72\%), и у 20 пациентов, получавших стрептокиназу (50\%). По степени восстановления коронарного кровотока по TIMI 2-й и 3-й степени отмечались у $10(25 \%)$ и $19(47,5 \%)$ пациентов в группе рекомбинантной проурокиназы и у $15(37,5 \%)$ и $5(12,5 \%)$ пациентов группы стрептокиназы соответственно.

Результаты исследования показали, что применение рекомбинантной проурокиназы приводит к более частному и полноценному восстановлению коронарного кровотока по сравнению со стрептокиназой [3].

Несмотря на то что рекомбинантная проурокиназа обладает фибринспецифичностью, при ее введении отмечались признаки системного фибринолиза: достоверное снижение уровня фибриногена (у $28 \%$ больных $<1,0$ г/л) и а2-антиплазмина. Вероятно, данные явления связаны с образованием двухцепочечной формы молекулы, лишенной фибринспецифичности. Также у больных отмечалось достоверное увеличение АЧТВ, что, вероятно, обусловлено дополнительным введением всем больным гепарина. «Малые» кровотечения (из мест пункций, кровоточивость десен, микрогематурия) отмечались у 26 (11\%) пациентов; «большие» кровотечения в $0,4 \%$ случаев. У одного пациента развился геморрагический инсульт.

В многоцентровое клиническое исследование, выполненное в 2002-2005 годах, было включено 1022 пациента с острым ИМ, 682 из которых получали ТЛТ рекомбинантной проурокиназой и $340-$ стрептокиназой. Все пациенты поступали в стационар в интервале $1,0-5,5$ часа от начала заболевания, введение препаратов начиналось в среднем через $4,1 \pm 0,3$ часа от начала заболевания или через $0,7 \pm 0,1$ часа от поступления. Рекомбинантную проурокиназу вводили по следующей схеме: $2000000 \mathrm{ME}$ болюсно + 4000 000-6000 000 МЕ в виде 60 минут инфузии. Стрептокиназу вводили инфузионно в дозе 1500
000 МЕ в течение 60 минут. Все пациенты получали общепринятую терапию инфаркта миокарда, в том числе стандартную антитромботическую терапию (антиагрегант: ацетилсалициловая кислота в дозе 300 мг в первые сутки ОИМ, затем - 100 мг/сутки, антикоагулянт: гепарин болюс 60 ЕД/кг (но не более 4000 ЕД), после чего - инфузия гепарина со скоростью 1000 ЕД/час на протяжении 48 часов под контролем активированного частичного тромбопластинового времени (АЧТВ) (цель - увеличение АЧТВ в 2-2,5 раза выше нормы (N 25-35 секунд) - в среднем до 50-70 секунд), при введении гепарина на догоспитальном этапе болюс не назначался, скорость инфузии определялась на основании данных АЧТВ при поступлении).

Введение рекомбинантной проурокиназы хорошо переносилось всеми пациентами. Непосредственно во время введения и после него не было отмечено аллергических реакций, явлений индивидуальной непереносимости, резкого снижения артериального давления, снижения частоты сердечных сокращений, которые обычно отмечаются на фоне терапии стрептокиназой.

По данным исследований ЭКГ, в группе из 682 больных, пролеченных рекомбинантной проурокиназой, коронарная реперфузия была достигнута у 504 (74\%) пациентов, в группе 340 больных, пролеченных стрептокиназой, - у 162 (48\%) пациентов.

У 48 пациентов с рецидивом ИМ в течение госпитального периода проводилось повторное введение рекомбинантной проурокиназы, что привело к восстановлению коронарного кровотока в $75 \%$ случаев.

При введении рекомбинантной проурокиназы в дозе 8000000 МЕ отмечалось небольшое снижение уровня фибриногена (на $47 \%$ от исходного уровня против $84 \%$ после стрептокиназы) к 3 часам после ее введения, которое восстанавливалось до нормальных значений через 10 часов после начала терапии. При данной дозе препарата также наблюдалось значительное снижение концентраций а2-атиплазмина и плазминогена, которые восстанавливались только после 2 суток. В первые часы после ТЛТ у всех пациентов отмечалось достоверное увеличение АЧТВ, связанное, вероятно, с дополнительным введением пациентам гепарина. В группе, получавшей терапию рекомбинантной проурокиназой, «малые и умеренные» кровотечения (из мест пункций, кровоточивость десен, микрогематурия, снижение гемоглобина $<5$ г/дл) отмечались у 109 (15,9\%) пациентов; «большие» кровотечения (геморрагический инсульт или гемоглобин $>5$ г/ дл) - у 7 пациентов (1,0\%). Из них у 2 больных развился геморрагический инсульт $(0,3 \%)$; оба больные выжили, но у одного сохранилась тяжелая неврологическая симптоматика. У 5 пациентов зафиксированы желудочно-кишечные кровотечения, потребовавшие переливания крови и проведения экстренной гастрофиброскопии для диагностики и лечения развившихся осложнений. Кровотечения, потребовавшие трансфузии крови, составляли 0,15 и 2,6\% для рекомбинантной проурокиназы и стрептокиназы соответственно.

В период 2012-2014 годов в ряде клиник ЦФО РФ было проведено открытое сравнительное рандомизи- 
рованное многоцентровое клиническое исследование эффективности и безопасности применения рекомбинантной проурокиназы, лиофилизат для приготовления раствора для внутривенного введения $2000000 \mathrm{ME}$ по схеме «двойной болюс» в сравнении со схемой «болюс + инфузия» в комплексной терапии острого инфаркта миокарда с подъемом сегмента ST. В исследование было включено 80 пациентов. Эффективность терапии оценивалась по летальности от ИМ к 14 и 60 дням исследования. Вторичной точкой оценки эффективности являлась частота восстановления коронарного кровотока по ЭКГ-признакам.

В ходе исследования было зарегистрировано пять летальных случаев: четыре в группе, получавшей рекомбинантную проурокиназу по схеме «болюс + инфузия», и один - в группе, получавшей препарат по схеме двойного болюса. Все смертельные исходы были зафиксированы на госпитальном этапе (до 14 суток). Результаты анализа выживаемости показали отсутствие статистически значимых различий между исследуемыми группами.

При оценке реперфузии миокарда, по данным ЭКГ, снижение сегмента ST более чем на $50 \%$ к 180-й минуте было зарегистрировано у 24 пациентов в группе, получавшей препарат по схеме двойного болюса, и у 28 пациентов в группе сравнения. По этому показателю различие между группами оказалось равным 5\%, что свидетельствует о не меньшей эффективности исследуемого способа введения рекомбинантной проурокиназы по сравнению со схемой «болюс + инфузия».

В ходе исследования было зарегистрировано 5 серьезных нежелательных явлений (СНЯ), завершившихся летальным исходом. В группе, применявшей рекомбинантную проурокиназу по схеме двойного болюса, СНЯ развилось у 1 пациента, в группе, применявшей препарат по схеме «болюс + инфузия», - у 4 пациентов. Все СНЯ не имели связи с введением препарата.

В работе В.А. Егоровой и др. представлены результаты изучения влияния антикоагулянтной терапии нефракционированным гепарином (НФГ) и низкомолекулярным гепарином (НМГ) на эффективность тромболитической терапии рекомбинантной проурокиназы. В исследование были включены 55 пациентов (42 мужчины и 13 женщин) в возрасте от 35 до 80 лет (в среднем $56 \pm 1,5$ лет). Пациентам проводили ТЛТ рекомбинантной проурокиназой по стандартной схеме. Одновременно с ТЛТ начинали введение гепаринов. Первая группа пациентов получала НФГ («Биохеми ГмбХ», Австрия): болюс 60 ЕД/кг с последующей инфузией с начальной скоростью 15 ЕД/кг/час в течение 3 суток. Скорость инфузии титровалась по показателю АЧТВ. Оптимальными считали значения АЧТВ от 50 до 75 секунд. Вторая группа пациентов получала терапию НМГ эноксапарином (клексан): болюс 30 мг и под кожу живота в дозе 1 мг (100 анти-Ха ЕД)/кг массы тела каждые 12 часов в течение 3 суток. На момент выписки и к концу первого года наблюдения при оценке прогноза учитывались случаи ишемии миокарда, развития повторного инфаркта миокарда, смерти, реваскуляриза- ции миокарда (транслюминальная баллонная коронарная ангиопластика + аортокоронарное шунтирование), недостаточности кровообращения. При подсчете суммы неблагоприятных исходов (суммарной конечной точки) учитывали число пациентов, у которых была отмечена хотя бы одна из указанных конечных точек, независимо от общего числа осложнений у каждого пациента. По результатам исследования группы НФГ и эноксапарина по частоте реперфузии коронарного кровотока достоверно не различались, она была достигнута у 19 (73\%) пациентов в группе НФГ и 23 (79\%) пациентов в группе эноксапарина.

Непереносимости, аллергических реакций и тромбоцитопении к 14-му дню наблюдения на рекомбинантную проурокиназу не отмечалось. Реперфузионные аритмии, требующие медикаментозной и инструментальной коррекции, в группе НФГ встречались у $5(19,2 \%)$ пациентов, в группе эноксапарина - у $5(17,2 \%)$ пациентов. На фоне проведения ТЛТ артериальная гипотония в группе НФГ была зарегистрирована у $3(11,5 \%)$ пациентов (у 2 больных тромболизис был неэффективным), в группе эноксапарина случаев гипотонии отмечено не было.

Терапия гепаринами в течение 3 суток продолжалась у $49(89 \%)$ пациентов. В группе НФГ у одного больного гепарин был отменен на 2-е сутки в связи с развившейся макрогематурией. Больших кровотечений не было. Во второй группе введение эноксапарина было досрочно прекращено 5 пациентам: у 2 больных по причине смерти в течение 3 часов после госпитализации; у 2 больных - в связи с развитием желудочно-кишечного кровотечения на фоне тромболизиса; у одного больного - в связи с развившейся на 2-е сутки макрогематурией. Частота малых кровотечений составила $42,3 \%$ в группе НФГ и $44,8 \%$ в группе эноксапарина. Отмечено 2 случая аллергических реакций на эноксапарин в виде питехиальной сыпи, купировавшейся назначением антигистаминных препаратов.

Группы антикоагулянтной терапии по клиническим исходам в течение госпитального периода и 1-го года амбулаторного наблюдения достоверно не различались. В период госпитализации ранняя постинфарктная стенокардия отмечена у 6 пациентов в группе НФГ и у 7 в группе эноксапарина. Все пациенты, кроме одного из группы НФГ, имели косвенные признаки реперфузии коронарной артерии. ТБА со стентированием выполнена 2 пациентам в группе НФГ и 5 - в группе эноксапарина. Остальным была подобрана антиангинальная терапия. Годовая летальность в группе НФГ составила $2(7,7 \%)$ пациента, в то время как в группе эноксапарина $-4(13,8 \%)$ пациента. Повторный инфаркт развился у $2(8,3 \%)$ пациентов в группе НФГ и у $3(12,5 \%)$ пациентов в группе эноксапарина. Постинфарктная стенокардия отмечалась у 28 (56\%) пациентов - по 14 в каждой группе. Обострение ИБС, потребовавшее госпитализации, отмечалось у 8 больных (31\%) в группе НФГ и у 6 больных $(20,7 \%)$ в группе эноксапарина. Реваскуляризации подверглись $9(37,5 \%)$ пациентов в группе НФГ и 7 (28\%) пациентам в группе эноксапарина. Не имел ос- 
ложнений за указанный период наблюдения 21 (38,8\%) больной. Таким образом, прогноз заболевания на фоне терапии НФГ и эноксапарином достоверно не различался, что может указывать на сопоставимую эффективность препаратов.

Группы НФГ и эноксапарина по исходному уровню фибриногена и плазминогена, а также их динамике в ходе ТЛТ не различались. Значительное снижение фибриногена и плазминогена через 3 часа после начала ТЛТ свидетельствует о том, что в использованных дозах рекомбинантная проурокиназа вызывала значительную системную активацию фибринолиза. К моменту выписки уровень фибриногена повысился в обеих группах, в группе НФГ различие было достоверным.

Результаты исследования показали, что рекомбинантная проурокиназа обеспечивает высокую частоту восстановления коронарного кровотока у больных острым инфарктом миокарда. Достоверных различий по эффективности тромболизиса, частоте осложнений и динамике Д-димера между группами НФГ и эноксапарина выявлено не было. У больных острым инфарктом миокарда уровень Д-димера при поступлении превышал верхнюю границу нормы, значительно повышался к концу терапии гепаринами и снижался до исходных значений к моменту выписки. Достоверных связей исходных уровней АТИФ, плазминогена и его динамики в ходе ТЛТ с реперфузией коронарной артерии выявлено не было.

Результаты клинических исследований свидетельствуют о высокой эффективности и безопасности рекомбинантной проурокиназы у пациентов с острым инфарктом миокарда как в режиме «болюс + инфузия», так и в режиме «двойной болюс».

\section{Фармакоинвазивный подход}

Важным периодом в истории тромболизиса стало внедрение ангиографического контроля эффективности ТЛТ в клинике, что впоследствии стало эталонным контролем в международных многоцентровых клинических исследованиях тромболитической терапии по протоколу TIMI. По результатам многочисленных исследований (AIMS, ASSET, ASSENT I-III, EMERAS, EMIP, GISSI-I,II, GREAT, ISAM, ISSIS-2, ISSIS-3, LATE, MITI, TEAHAT, USIM) можно с уверенностью утверждать, что своевременное проведение ТЛТ в тех случаях, когда выполнение ЧКВ в рекомендованные сроки невозможно, статистически значимо снижает летальность от ИМпST, уменьшает риск развития осложнений данного заболевания $[4,5]$.

Фармакоинвазивная стратегия - это тактика ведения пациентов с ОИМпST, при которой после успешной ТЛТ выполняется ангиография и ЧКВ. В РФ в 2018 году работают 330 центров рентгенэндоваскулярной диагностики и лечения [6].

Тем не менее, согласно федеральному регистру, в 2014 году ЧКВ выполнялось в $11,5 \%$ случаев, а ТЛТ проводилась в $26,7 \%$ случаев среди пациентов с ОИМ c ST [7]. Внушительное количество пациентов не по- лучило своевременной реперфузионной терапии. Задержки в начале реперфузионной терапии в любой ее форме доказано приводят к увеличению смертности от инфаркта миокарда.

Исходя из полученной статистики становится очевидным, что не везде возможно своевременно доставить пациента в ЛПУ с компетентной ангиографической службой, а значит, рекомендованные сроки до начала реперфузии могут быть не соблюдены.

Если интервал «диагноз-баллон» не может соответствовать принятым нормам, согласно международным рекомендациям, применение фармакоинвазивной стратегии может стать методом выбора.

Только в 2016 году, по данным исследования STREAM [8-13], в которое были включены 1915 пациентов, у больных ИМпST ТЛТ с введением тенектеплазы, выполненная перед транспортировкой пациента в больницу с возможностями для проведения ЧКВ с последующей своевременной коронарной ангиографией, является столь же эффективным, как и первичное ЧКВ. Частота первичной конечной точки - комбинации смерти от всех причин, кардиогенного шока, застойной сердечной недостаточности и повторного ИМ в течение 30 дней - была сопоставимой в группах первичного ЧКВ и тенектеплазы (14,3 vs $12,4 \%$ соответственно, $\mathrm{p}=0,21)$. Снижение частоты первичной конечной точки в группе фармакоинвазивной стратегии было достигнуто в основном за счет снижения рисков кардиогенного шока и застойной сердечной недостаточности. Таким образом, выполнение тромболитической терапии на догоспитальном этапе в сочетании со своевременно выполненным ЧКВ приводит к эффективной реперфузии миокарда у больных, которые обращаются за медицинской помощью в ранние сроки после развития ИМ, но у которых выполнение первичного ЧКВ на коронарных артериях в рекомендованные сроки невозможно.

Эффективность как первичного ЧКВ, так и ТЛТ уменьшается с течением времени от момента появления симптомов, возможность восстановить проходимость сосуда со временем намного выше у ЧКВ. В случае если в течение 2 часов проведение ЧКВ не представляется возможным, рекомендовано начало ТЛТ. Ряд клинических исследований показал, что исходы лечения пациентов с ранним началом ТЛТ не уступают ЧКВ.

В 2017 году Европейское общество кардиологов опубликовало очередные обновленные Рекомендации по ведению пациентов с ОИМпST, в которых по-прежнему ТЛТ остается рекомендованной к применению в случае невозможности своевременно провести ЧКВ [14], что подтверждают результаты исследования STREAM [8-13].

Обновленные рекомендации по реваскуляризации Европейского общества кардиологов от 2018 года также затрагивают особенности применения ТЛТ с последующей ЧКВ. Таким образом, ТЛТ является признанным этапом реперфузии при невозможности своевременного начала ЧКВ [2]. 
Наш опыт применения фармакоинвазивной стратегии с использованием тромболитического препарата III поколения рекомбинантная проурокиназа.

В работе проводилась оценка клинической эффективности, безопасности и результатов лечения больных инфарктом миокарда тромболитическим препаратом третьего поколения пуролазой на догоспитальном и госпитальном этапе при фармакоинвазивном подходе.

В исследование были включены все пациенты с ИМ с подъемом сегмента ST, поступившие в отделение неотложной кардиологии в период с 2003 по 2017 год, которым проводилась ТЛТ пуролазой как на догоспитальном, так и на госпитальном этапе в течение 6 часов после первых признаков развития основного заболевания, с последующим чрескожным коронарным вмешательством (ЧКВ). Группа сравнения - больные с диагнозом «острый инфаркт миокарда», которым проводился тромболизис стрептокиназой. Критерии включения и исключения соответствовали общепринятым показаниям к ТЛТ и ЧКВ Работа выполнялась ретроспективно и проспективно. Проанализирован ряд параметров: условия проведения ТЛТ (догоспитально, госпитально), время начала реперфузионной терапии, наличие противопоказаний к ТЛТ, результаты коронарографии (окклюзия или резидуальный стеноз; кровоток по классификации ТІМІ), факт исхода заболевания на момент выписки (жив/смерть). Оценка кровотока производилась по общепринятым критериям TIMI. В дальнейшем производилось анкетирование пациентов посредством телефонного звонка.

В исследование были включены 2478 пациентов, из них 1449 проводилась ТЛТ пуролазой, 1029 - стрептокиназой. Группы сопоставимы по полу, возрасту, локализации ИМ.

Результаты: реперфузия (как основной критерий эффективности препарата), по данным коронарографии, была достигнута в $72,1 \%$ случаев в группе пуролазы и в $54,4 \%$ случаев в группе стрептокиназы $(\mathrm{p}=0,000)$. Малые кровотечения составили $3,7 \%$ в группе пуролазы (54 человека) и $11,5 \%$ в группе стрептокиназы (118 человек). Большие кровотечения - $0,3 \%$ в группе пуролазы (5 человек) и $2,7 \%$ в группе стрептокиназы (28 человек). Аллергическая реакция $-0,06 \%$ (1 случай) в группе пуролазы и $0,38 \%$ в группе стрептокиназы (4 случая). Различия статистически достоверны $(\mathrm{p}<0,001)$. Особенности коронарной ангиографии и эндоваскулярных вмешательств после ранней (при отсутствии реперфузии) и отсроченной на 3-24 часа ангиографии будут представлены в статье, специально посвященной этому вопросу. Выживаемость в период госпитализации статистически значимо не отличалась.

Рекомбинантная проурокиназа - это эффективный и безопасный фибринолитический препарат для лечения больных ИМ с подъемом сегмента ST, который может быть использован при фармакоинвазивном подходе к лечению заболевания.

\section{ЗакАючение}

Важность раннего начала тромболитической терапии с целью максимального улучшения прогноза остается столь же очевидной, как и после внедрения эндоваскулярных способов восстановления коронарного кровотока.

При всех преимуществах первичного коронарного вмешательства (ангиопластика и/или стентирование) ТЛТ не утратила основных показаний в лечении острого ИМ. Это обусловлено рядом причин: невозможностью инвазивного вмешательства у большинства пациентов с ОКС и невозможностью проведения его в определенные временные интервалы (90-120 минут). При этом не стоит противопоставлять медикаментозный и инвазивный методы лечения больных ИМ. Вместе они составляют фармакоинвазивный подход, когда незамедлительно проводится ТЛТ с последующей транспортировкой больных в инвазивный центр для проведения коронарной ангиографии и при наличии показаний эндоваскулярного лечения (ангиопластика, стентирование).

Применение ТЛТ на догоспитальном этапе значительно повысило эффективность лечения фибринолитическими препаратами, в частности пуролазой, за счет простоты введения и безопасности применения.

Рекомбинантная проурокиназа - один из наиболее распространенных препаратов, разрешенных к применению в РФ; препарат сопоставим по эффективности с ТАП и выигрывает по экономической эффективности.

Именно рекомбинантная проурокиназа соответствует требованиям, предъявляемым к тромболитическим препаратам в Европе, и может успешно использоваться по показаниям.

Авторы заявляют об отсутствии конфликта интересов. Поступила 28.06.2019 Принята в печать 15.10.2019

\section{ЛИТЕРАТУРА/REFERENCES}

1. Диагностика и лечение больных острым инфарктом миокарда с подбемом сегмента ST электрокардиограммы. Рекомендации Общества специалистов по неотложной кардиологии и профильной комиссии по кардиологии. М.: МЗРФ, 2014. [Diagnostics and treatment of patients with STEMI. Recommendations of Society of Specialists in Emergency Cardiology and Relevant Committee in cardiology. M.: Ministry of Health of Russian Federation, 2014].

2. 2017 ESC Guidelines for the management of acute myocardial infarction in patients presenting with ST-segment elevation: The Task Force for the management of acute myocardial infarction in patients presenting with STsegment elevation of the European Society of Cardiology (ESC) Ibanez B., James S., Agewall S. European Heart Journal. 2018;39 (2):119-177.

3. Староверов И.И., Коткин К.Л. Пуролаза - отечественный тромболитический препарат третьего поколения. Использование при остром инфаркте миокарда. РМЖ. 2004;9:538-542. [Staroverov I., Kotkin K Purolase - trombolytic drug of the third generation produced in Russia. Usage in acute myocardial infarction. RMJ. 2004;9:538-542].

4. Sinnaeve P., Alexander J., Belmans A. et al. One-year follow-up of the ASSENT-2 trial: a double-blind, randomized comparison of single-bolus tenecteplase and front-loaded alteplase in 16,949 patients with ST-elevation acute myocardial infarction. Am Heart J. 2003;146(1):27-32.

5. Van De Werf F., Adgey J., Ardissino D. et al. Single-bolus tenecteplase compared with front-loaded alteplase in acute myocardial infarction: the ASSENT-2 double-blind randomised trial. Lancet. 1999;354(9180):716-22. 
6. Алекян Б.Г., Стаферов А.В., Григорян А.М. Рентгеноэндоваскулярная диагностика и лечение заболеваний сердца и сосудов в Российской Федерации. 2017. Эндоваскулярная хирургия. 2018;5 (2):93-240. [Alekyan B. Staferov A., Grigoryan A. X-ray endovascular diagnosis and treatment of heart and vascular diseases in the Russian Federation. Endovascular Surgery. 2018;5 (2):93-240].

7. Посненкова О.М., Коротин А.С., Киселев А.Р. и др. Выполнение рекомендованных лечебных мероприятий у больных с острым коронарным синдромом в 2014 году: отчет по данным федерального регистра. Кардио-ИТ. 2015;2(1): e0101. [Posnenkova O., Korotin A., Kiselev A et al. Implementation of the recommended therapeutic measures in patients with acute coronary syndrome in 2014: report of the Federal register of patients. Cardio-IT. 2015;2(1): e0101].

8. Armstrong P.W., Gershlick A.H., Goldstein P. et al. Fibrinolysis or primary PCI in ST-segment elevation myocardial infarction. N. Engl. J. Med. Apr 2013;368(15):1379-87
9. Armstrong P.W. et al. The Strategic Reperfusion Early After Myocardial Infarction (STREAM) study. Am Heart J. 2010;160:30-35(e31).

10. Bates E.R. Evolution from fibrinolytic therapy to a fibrinolytic strategy for patients with ST-segment-elevation myocardial infarction. Circulation. 2014;130(14):1133-1135).

11. Gershlick A. et al. Impact of a pharmacoinvasive strategy when delays to primary PCI are prolonged. Heart. 2015;101:692-698.

12. Sinnaeve P.R. et al. STEMI patients randomized to a pharmaco-invasive strategy or primary PCI: The STREAM 1-Year mortality follow-up. Circulation. 2014; 130 (14):1139-1145.

13. Shavadia J. et al. Infarct size, shock, and heart failure: does reperfusion strategy matter in early presenting patients with ST-segment elevation myocardial infarction? J Am Heart Assoc. 2015;4(8):e002049.

14. 2017 ESC Guidelines for the management of acute myocardial infarction in patients presenting with ST-segment elevation. European Heart Journal. 2017;00:1-66 